\title{
ORGANIZAÇÃO DA EDUCAÇÃO ESPECIAL EM UMA REDE ESTADUAL DE ENSINO SOB O PRISMA DAS POLÍTICAS PÚBLICAS
}

\author{
ORGANIZACIÓN DE LA EDUCACIÓN ESPECIAL EN UNA RED ESTADUAL DE \\ ENSEÑANZA BAJO EL PRISMA DE LAS POLÍTICAS PÚBLICAS
}

\author{
ORGANIZATION OF SPECIAL EDUCATION IN A STATE NETWORK UNDER \\ PUBLIC POLICY PRISMA
}

Geandra Cláudia Silva SANTOS ${ }^{1}$

\begin{abstract}
RESUMO: Na atualidade, surgem oportunidades de acesso aos direitos educacionais com a aprovação de documentos inseridos no repertório das políticas públicas, que garantem aos alunos com Necessidades Educacionais Especiais (NEE) a obrigatoriedade da matrícula na escola comum e participar do atendimento em todos os níveis de ensino. O presente estudo objetivo descrever a organização da educação especial, na rede estadual de ensino do Ceará, a partir da Constituição de 1988, para identificar articulações com as políticas públicas nacionais e o desenvolvimento de iniciativas próprias direcionadas à efetivação da inclusão escolar dos alunos com NEE. Para tanto, realizou-se uma pesquisa documental, direcionada ao estudo de dispositivos legais e técnicos disponíveis no âmbito da administração da educação cearense. As estatísticas demonstraram o crescimento das matrículas dos alunos na escola comum, em substituição às classes/escolas especializadas, expressão das políticas públicas nacionais, que ratificam, pelo menos, em termos legais, os preceitos da educação inclusiva.
\end{abstract}

PALAVRAS-CHAVE: Educação especial. Políticas públicas. Rede estadual de ensino. Perspectiva inclusiva.

RESUMEN: En la actualidad, surgen oportunidades de acceso a los derechos educativos con la aprobación de documentos insertados en el repertorio de las políticas públicas, que garantizan a los alumnos con Necesidades Educativas Especiales (NEE) la obligatoriedad de la matrícula en la escuela común y participar de la atención en todos los niveles de educativos. El presente estudio desea describir la organización de la educación especial, en la red estadual de enseñanza de Ceará, a partir de la Constitución de 1988, para identificar articulaciones con las políticas públicas nacionales y el desarrollo de iniciativas propias dirigidas a la efectividad de la inclusión escolar de los alumnos con NEE. Para estos fines, se realizó una investigación documental, dirigida al estudio de dispositivos legales y técnicos disponibles en el ámbito de la administración de la educación cearense. Las estadísticas demostraron el crecimiento de las matrículas de los alumnos en la escuela común, en sustitución de las clases / escuelas especializadas, expresión de las políticas públicas nacionales, que ratifican, al menos, en términos legales, los preceptos de la educación inclusiva.

\footnotetext{
${ }^{1}$ Universidade Estadual do Ceará (UECE), Fortaleza - CE - Brasil. Professora do Programa de Pós-graduação em
} Educação - PPGE. ORCID: <http://orcid.org/0000-0002-7782-6316>. E-mail: geandra.santos@uece.br 
PALABRAS CLAVE: Educación especial. Políticas públicas. Redes staduales de ensñanzas. Perspectiva inclusiva.

ABSTRACT: At present, opportunities for access to educational rights come up with the approval of documents inserted in the repertoire of public policies, which guarantee to students with special educational needs (NEE) the compulsory enrollment in the regular school and participating in the attendance at all levels of education. The objective of this study is to describe the organization of special education in Ceara the state education system, as of the 1988 Constitution, to identify articulations with national public policies and the development of own initiatives directed at the effective inclusion of students with NEE. For that, a documentary research was conducted, aimed to the study of legal and technical devices available within the scope of the administration of education in Ceará. Statistics have shown the growth of student enrollments in the regular schools, in replacement to the specialized classes / schools, the expression of national public policies, which ratify, at least in legal terms, the precepts of inclusive education.

KEYWORDS: Special education. Public policy. State education network. Inclusive perspective.

\section{Introdução}

As primeiras iniciativas de atendimento às pessoas com deficiência no Brasil foram oriundas de ações isoladas de indivíduos que se mobilizaram na tentativa de prestar algum atendimento, que, em geral, se caracterizava como assistencial e de natureza privada.

Na década de 1960, registram-se ações oriundas do poder público à luz dos direitos contemplados na Lei de Diretrizes e Bases da Educação Nacional, LDB n 4024/61. Nos anos de 1970, desenvolveram-se ações de apoio técnico-pedagógico às instituições especializadas nos estados e munícipios, além da criação/ampliação do número de classes especiais no âmbito da escola pública.

Essas iniciativas do poder público que ampliaram espaços de direitos às pessoas com deficiência devem-se a intensificação das lutas dos movimentos sociais (LANCILLOTTI, 2003). As políticas públicas correspondem a programas de ações, que envolvem “[...] sempre uma determinada definição social da realidade, expressa no modo de compreensão das causas dos problemas a serem solucionados, bem como nas propostas para a sua solução" (DOURADO, 2010, p. 30), em um contexto dinâmico de projetos em disputa, de modo que suas implementações nem sempre condizem com os seus planejamentos.

Com a promulgação da Constituição Federal de 1988, sob o signo da abertura democrática no país, são produzidas, gradativamente, condições políticas e sociais mais propícias à criação de oportunidades educacionais às pessoas com deficiência, intensificadas a 
partir dos movimentos internacionais em defesa da educação inclusiva, tendo como representante emblemática a Declaração de Salamanca. A educação inclusiva, segundo esse documento, defende que as pessoas com necessidades educacionais especiais (NEE) devem ter acesso às escolas comuns orientadas por uma pedagogia integradora, para combater todas as formas de discriminação e permitir acesso ao conhecimento (BRASIL, 2008).

Nessa perspectiva, a LDB 9394/96, no capítulo V, a Educação Especial é estabelecida como modalidade de educação escolar a ser oferecida preferencialmente na rede regular de ensino e garante o atendimento educacional especializado ao seu público-alvo (BRASIL, 2008).

No início do século XXI a aprovação das Diretrizes Nacionais para a Educação Especial na Educação Básica, em 2001, reforça a obrigatoriedade da matrícula de todos os alunos com NEE e atribui à escola a garantia do atendimento e das condições necessárias à educação de qualidade para todos (BRASIL, 2008).

A Política Nacional de Educação Especial na perspectiva inclusiva (PNEEPI), de 2008, e os documentos decorrentes de sua elaboração, visa a superação de ações segregadoras e alheias ao caráter pedagógico da educação dos alunos com NEE, contribuindo para ampliação do acesso à escolarização com o suporte do atendimento educacional especializado, que deve ser incorporado ao projeto pedagógico das instituições de educação básica e superior (BRASIL, 2008).

Considerando as mudanças ocorridas nos marcos regulatórios da educação especial na perspectiva inclusiva, com crescimento no quantitativo de alunos com NEE matriculados, como registram os censos escolares na última década, o presente estudo tem como objetivo descrever a organização da educação especial, na rede estadual de ensino do Ceará, por meio das políticas públicas aprovadas, a partir da Constituição Federal de 1988. Com isto, buscamos identificar articulações entre os marcos regulatórios estaduais e nacionais, bem como o desenvolvimento de iniciativas estaduais direcionadas à efetivação do paradigma da inclusão escolar dos alunos com NEE.

Para Pietro (2015), tendo em vista o exame das produções acadêmicas, a tendência dos Estados e Municípios brasileiros tem sido seguir as orientações das leis e políticas nacionais vigentes, acatando os princípios da educação inclusiva. Ao constatar que o número de pesquisas sobre o assunto tem aumentado, as temáticas investigadas se concentram nas práticas pedagógicas, em detrimento da análise das políticas públicas. Também constatamos essa lacuna, ao examinar a produção pertinente à realidade cearense. 
Destarte, este estudo reveste-se de relevância ao contribuir com a ampliação de produções que se debruçam sobre as políticas públicas definidas em nível estadual, como via de compreensão da tomada de decisões oriundas dos sistemas de ensino, para garantirem a efetivação dos direitos educacionais aos alunos com NEE.

Faz-se importante conhecer como cada governo interpreta e decide o cumprimento de suas reponsabilidades ante as finalidades preconizadas pela legislação nacional, respeitando seu percurso histórico e contextualizando os desafios a serem enfrentados na realidade local, nas abrangências estadual e municipal.

\section{Metodologia}

O estudo consiste em uma pesquisa bibliográfica e documental, de caráter descritivoanalítico, que se debruça sobre dados que ainda não foram analisados, pois os documentos acessados se encontram em estado original. Assim, eles podem ser reelaborados de acordo com a finalidade da pesquisa e o delineamento elaborado pelo pesquisador (MATOS, 2001), na análise.

Recolhemos documentos de abrangência internacional (Declaração de Salamanca), nacional (Constituição Federal de 1988, LDB 9394/96, Diretrizes Nacionais para Educação Especial, PNEEPI, Resolução Nº4/2009, Novo Plano Nacional de Educação) e estadual. Logo, o conjunto dos documentos de abrangência estadual, foco central da exploração e análise, compreendeu dispositivos legais e técnicos disponíveis no âmbito da administração da educação cearense.

Os documentos estaduais foram identificados por meio de busca direta em um órgão regional da administração da educação estadual, bem como no sítio oficial da Secretaria de Educação do Estado do Ceará (SEDUC). Definimos como documentos de interesse direto aqueles produzidos após a promulgação da Constituição de 1988: Constituição Estadual do Ceará (1989), Política Estadual de Educação Especial (1997), as Resoluções do Conselho de Estadual de Educação (CEE) N³61/2000, N³94/2004, N³36/2012, N 456/2016, Plano Estadual de Educação - Lei N. ${ }^{\circ} 16.025 / 2016$.

A análise centrou-se nos documentos estaduais, organizada por meio de uma linha cronológica propícia à identificação das definições legais e das tendências que orientam a previsão das ações na rede estadual de ensino, em uma perspectiva inclusiva, ao longo da 
temporalidade demarcada, além de verificar as articulações com os marcos regulatórios nacionais, realçando aspectos peculiares da realidade da educação especial no Ceará.

\section{Resultados e discussão}

Seguindo as definições da Constituição Federal de 1988, a Constituição do Estado do Ceará de 1989, no Capítulo II, que trata sobre a Educação, estabeleceu, no art. 215, § I, “[...] igualdade de condições para o acesso e a permanência na escola" (CEARÁ, 1989, p. 130), e, no artigo 218, § VI estabeleceu o "[...] atendimento educacional especializado aos portadores de deficiência em qualquer idade, preferencialmente na rede regular de ensino" (CEARÁ, 1989, p. 130).

As duas leis mencionadas apontam para manutenção da matrícula dos alunos com NEE em classes e escolas especiais. Na constituição cearense, no artigo 229, assegura-se o direito à educação em todos os graus “[...] quer em classes comuns, quer em classes especiais, quando isto se fizer necessário" (CEARÁ, 1989, p. 135).

$\mathrm{O}$ atendimento educacional especializado (AEE) emerge nas legislações supracitadas como alternativa pedagógica para inscrever os alunos com NEE na escolarização comum, por força dos direitos conquistados, desde a Constituição Federal de 1988 e ratificados pela Lei de Diretrizes e Bases da Educação Nacional LDB N 9.394/96. Com isso, desponta a criação de instituições e serviços, em parcerias celebradas entre os sistemas de ensino federal, estadual e municipal, com vistas à realização de ações de atendimento em áreas específicas.

Em 1996, no Ceará, houve a criação do Centro Integrado de Educação Especial, como o objetivo de promover ações específicas de atendimento voltadas ao desenvolvimento psicossocial dos alunos e sua integração nos espaços familiar, escolar e social (CEARÁ, 1997).

Em consonância com a LDB N 9394/96, a Secretaria de Educação do Estado do Ceará (SEDUC) lançou, no ano de 1997, a Política Estadual de Educação Especial (PEEE) calcada na defesa da escola inclusiva que "[...] deve propiciar um atendimento especializado que permita ao aluno, mesmo inserido no ensino regular, receber apoio pedagógico e instrucional, segundo as suas potencialidades e necessidades [...]" (CEARÁ, 1997, p. 11). O público-alvo da Educação Especial, conforme essa Política, são os alunos que apresentam deficiência mental, visual, auditiva, física, múltipla, altas habilidades e condutas típicas. Esses alunos correspondem ao público-alvo indicado pela Política Nacional de Educação Especial, de 1994. 
A PEEE defendeu, para o redimensionamento da Educação Especial no Ceará, a implantação dos núcleos de atendimento especializado, na capital e no interior do Estado, seguindo uma proposta de expansão, interiorização e inclusão do educando com NEE no ensino comum (CEARÁ, 1997), por meio de parcerias entre os governos estaduais e municipais. Os Núcleos de Apoio Pedagógico Especializados configuram-se como "espaços pedagógicos que contam com uma equipe multiprofissional, composta de pedagogos, assistentes sociais, psicólogos, fonoaudiólogos e terapeutas ocupacionais, equipados com recursos pedagógicos específicos" (CEARÁ, 2015).

Para Figueiredo (2003, p. 22), “Os princípios que norteiam a Política Estadual de Educação Especial do Estado do Ceará apontam para a garantia do acesso, permanência e terminalidade educacional da pessoa com necessidades educativas especiais".

Em 2004, o Conselho de Educação do Ceará aprovou a Resolução Nº 394/2004, fixando normas para a educação de alunos com NEE no sistema de ensino estadual, fundamentada no que determinou a LDB n 9.394/96, a Resolução nº 02/2001 e o Decreto no 3.956/2001.

No art. 01 da Resolução No 394/2004, as NEE foram definidas como sendo “[...] aquelas relacionadas às dificuldades de aprendizagem que interferem na escolarização de todo e qualquer aluno, temporárias ou permanentes” (CEARÁ, 2004, p. 1). O art. 02, do mesmo documento, especificou que os alunos com NEE são aqueles que apresentam: dificuldades acentuadas na aprendizagem ou limitações no desenvolvimento, dificuldades físicas e biológicas, dificuldades de comunicação, notável desempenho e elevada potencialidade em diferentes áreas.

Conforme o art. 09 dessa Resolução, “A educação especial será oferecida nas redes pública e privada, a partir da educação infantil” (CEARÁ, 2004, p.03). Já o art. 13 defende que a escola deve acolher os alunos com NEE, independentemente da sua deficiência, devendo o "[...] atendimento ser feito em classes comuns, em todos os níveis e modalidades de ensino, respeitadas as exigências pedagógicas recomendadas" (CEARÁ, 2004, p. 10). No que se refere aos serviços de atendimento especializado, o art. 14 estipulou que as escolas devem se organizar para oferecê-lo, de acordo com as especificidades dos alunos, por meio de vários serviços: salas de recursos, apoio pedagógico e psicopedagógico, serviços de itinerância.

A partir da operacionalização da PNEEPI, houve a expansão do acesso dos alunos com NEE à escolarização no ensino comum em nível nacional. No Ceará, também, na última década, houve crescimento das matrículas de alunos com NEE no ensino comum, se comparado ao aumento das matrículas em instituições especializadas. Balbinot (2016), em estudo recente 
sobre a evolução da educação especial no Ceará, no período de 2005 a 2014, constatou uma migração do atendimento dos alunos com NEE de escolas exclusivamente especializadas e de classes especiais para as classes comuns do ensino regular, nas instituições públicas e privadas.

Em vista disso, podemos assinalar, em alguma medida, a adesão à PNEEPI pelo governo cearense, visto que, segundo Bueno e Melletti (2013), a situação das matrículas convertem-se em indicadores relevantes à avaliação das políticas de educação especial.

Entretanto, Balbinot alerta que a quantidade de sujeitos atendidos pela educação especial em comparação com o total de alunos correspondia a apenas $01 \%$ da população com direito à educação especial. Balbinot retrata, em nível estadual, a exclusão histórica vivenciada pelo público da educação especial, impondo ao poder público, além do enfretamento dos desafios de natureza pedagógica (a promoção da aprendizagem daqueles alunos já matriculados), ainda permanece a tarefa de universalizar a matrícula, conforme preconiza o PNE.

Sobre a contradição identificada na realidade de matrículas no Ceará, a defasagem de atendimento a todo público-alvo da educação especial, apesar dos avanços quantitativos, Kassar (2011) ressalta a relevância dos diferentes setores da sociedade se envolverem em lutas que garantam a elaboração de políticas para toda população, ao contrário da configuração ainda vigente no país.

De fato, a ampliação do acesso à escolarização dos alunos com NEE gerou, para os sistemas de ensino, novas demandas à educação especial, que são atendidas conforme preconiza as diretrizes nacionais cujo foco direciona-se ao atendimento especializado, que também pode ser realizado em centros especializados, em parcerias com instituições privadas. No Ceará, em 2010, a SEDUC criou o Centro de Referência em Educação e Atendimento Especializado do Ceará - CREAECE, reunindo as demais instituições públicas de Atendimento Especializado do Estado em uma mesma instituição.

O CREACE desenvolve serviços de AEE, produção e transcrição de material didático acessível para alunos com deficiência visual, ações de formação continuada na área de educação especial, apoio e orientação às famílias ou responsáveis pelos alunos (CEARÁ, 2015). Segundo Matos (2012, p.65), o CREACE: "É uma instituição promotora de ações de política pública integrada, contando com a parceria das instituições públicas e privadas e da comunidade em geral”.

No ano de 2012, o Conselho Estadual de Educação (CEE) publicou a Resolução N ${ }^{\circ}$ 436/2012, que trata do AEE, conforme preconiza a PNEEPI, pois o sistema de ensino não 
elaborou uma nova política estadual de educação especial. Em 2016, este documento foi revogado pela Resolução $N^{\circ} 456 / 2016$, que fixa normas para a Educação Especial e para o AEE, no âmbito do sistema de ensino do Ceará.

A Resolução n ${ }^{\circ}$ 456/2016 define, no artigo 1º, a "Educação Especial, como modalidade transversal a todos os níveis, etapas e modalidades de ensino, é parte integrante da educação regular, devendo ser prevista no projeto pedagógico da unidade escolar" (CEARÁ, 2016a, p. 01). O artigo $\mathrm{N}^{\circ} 02$ delibera como público-alvo da educação especial os alunos com deficiência, transtornos globais do desenvolvimento e altas habilidades/superdotação.

$\mathrm{O}$ artigo $\mathrm{N}^{\circ} 09$ obriga os sistemas de ensino ofertarem $\mathrm{O}$ AEE, “[...] que tem como função identificar, elaborar e organizar recursos pedagógicos de acessibilidade que atenuem as barreiras para a plena participação dos alunos" (CEARÁ, 2016a, 03). O mesmo artigo preconiza que o AEE deve complementar e/ou suplementar a formação dos alunos no ensino comum, a ser realizado, prioritariamente, na sala de recursos multifuncionais (SRM) da escola regular, mas também pode ocorrer em centros de atendimento educacional públicos e privado, além de prever, no artigo $\mathrm{N}^{\circ} 11$, outros espaços para sua realização, como os ambientes hospitalar e domiciliar.

O profissional, para atuar no AEE, segundo o art.17, deve ter “[...] formação inicial que o habilite para o exercício da docência e formação específica na Educação Especial/Inclusiva ou cursos de formação em AEE" (CEARÁ, 2016a, p. 06).

O Plano Estadual de Educação, Lei N. ${ }^{\circ}$ 16.025/2016, dentre outros aspectos que divergem da Meta 04, do Plano Nacional de Educação, estão os seguintes: acréscimo dos alunos como distúrbios alimentares, no conjunto de alunos que têm direito ao AEE. Nas estratégias prevê ampliação do número de salas de recursos multifuncionais e implantação de centros especializados, como o CREACE, em macrorregionais do estado; garante a participação de profissionais para apoiar os alunos com NEE na escola, além de garantir a regulamentação da função do profissional Cuidador.

O PEE compromete-se, também, com a qualificação do atendimento e o desempenho dos professores das SRM, por meio de formação continuada e garantia de acompanhamento pedagógico sistematizado, além da aquisição de recursos materiais necessários ao desenvolvimento dos serviços de AEE, nas instituições de ensino estaduais (CEARÁ, 2016b). 


\section{Considerações finais}

Na introdução, lançamos mão do conceito de políticas públicas como expressão da análise dos problemas identificados na sociedade e o consequente direcionamento das soluções a serem concretizadas. Em vista disto, as políticas públicas do estado do Ceará examinadas ratificam as soluções contidas nos marcos regulatórios pertinentes à educação especial em âmbito nacional, ao longo dos anos, seguindo, hordiernamente, os preceitos da educação inclusiva, conforme preconiza a PNEEPI. Identificamos isto, inclusive, nos dados que registram as matrículas dos alunos com NEE no ensino comum com AEE.

Observamos nas Resoluções $n^{\circ}$ 436/2012 e n 456/2016 a expressão do momento em que a área de educação especial, no Brasil, se encontra atualmente, ao fundamentar-se na PNEEPI e na Resolução No 4/2009, visando a implantação do AEE nas instituições de ensino regular, para garantir o acesso à escolarização em todos os níveis, ao vinculá-lo ao projeto pedagógico das escolas.

As resoluções mantêm os mesmos grupos de estudantes que compõem o público-alvo da educação especial estabelecido pela PNEEPI, entretanto, no PEE está garantida a inclusão dos alunos com distúrbios alimentares no AEE, configurando-se como definição própria, pois extrapola quaisquer outras já estabelecidas.

Vale destacar que a resolução ${ }^{\circ}$ 456/2016 parece cumprir a função de atualizar a PEEE, que não teve uma nova edição, após o ano de 1997, apesar do sistema de ensino demonstrar seguir rigorosamente o fluxo de elaboração dos dispositivos legais nacionais.

O PEE demonstrou a intenção de implantar serviços especializados, através do CREACE, que passa a ser mais valorizado, em detrimento dos NAPE, principalmente, após a aprovação do PEE, conforme preconizado no Plano Nacional de Educação, com a retomada do fortalecimento dos serviços especializados em centros multidisciplinares de apoio, com parcerias entre instituições públicas e privadas. Mantem-se, portanto, a tendência de retomada do fortalecimento da iniciativa privada na oferta de serviço da educação especial, conforme preconiza o PNE.

Outro aspecto que também se consolida, pelo menos em termos legais, é a regulamentação das funções de apoio pedagógico, como por exemplo do profissional Cuidador, incumbido de atividades relacionadas aos cuidados de higiene e alimentação dos alunos. Este aspecto ainda é muito debatido e, por vezes, gera polêmicas, pois deve ser assumido e regulamentado em cada sistema de ensino estadual e municipal. 
Possivelmente os documentos expressam uma tendência do governo estadual em garantir investimentos financeiros e materiais próprios, quando se trata da expansão dos serviços das SRM e do CREACE, bem como das ações de formação dos profissionais da educação especial, quando se observa um declínio dos investimentos federais nessa área.

Diante do exposto entendemos que, a partir dos achados da pesquisa, será relevante e oportuno a realização de novas pesquisas direcionadas especificamente à investigação empírica, para constatar se a tendência observada nos dispositivos legais vigentes, na realidade cearense, tem se efetivado na prática educativa, resultando em oportunidades mais inclusivas aos alunos com NEE.

Novos diálogos entre a realidade educacional e as políticas públicas precisam ser elaborados objetivando gerar maior clareza e conhecimentos sobre os desafios impostos pelas novas reformas em curso, no Brasil, para que sejamos capazes de defender os direitos conquistados historicamente, para a população excluída, como os alunos com NEE. O debate científico e politicamente engajado na luta em favor da justiça social e da emancipação humana, se configura como uma alternativa importante nos dias atuais.

AGRADECIMENTOS: À Fundação Cearense de Apoio ao Desenvolvimento Científico e Tecnológico (FUNCAP).

\section{REFERÊNCIAS}

BALBINOT. A. D. A Educação Especial no Ceará: um estudo da evolução dos indicadores entre 2005 e 2014. Cinergis, Santa Cruz do Sul, v. 17, n.01, p.:74-79, jan./mar., 2016. Disponível em: https://online.unisc.br/seer/index.php/cinergis/article/view/7147. Acesso em: 11 jun. 2018.

BUENO, J. G.; MELETTI, S. M. F. A Escolarização de Alunos com Deficiência intelectual: Análises dos Indicadores Educacionais Brasileiros. In: BUENO, J. G.; MELETTI, S. M. F. (Orgs.) Políticas Públicas, Escolarização de Alunos com Deficiência e a Pesquisa Nacional. Araraquara, SP: Junqueira \& Marin, 2013.

CEARÁ. Constituição do Estado do Ceará. Fortaleza, SEGOV, 1989.

CEARÁ. Política Estadual de Educação Especial: integração com responsabilidade. Fortaleza, CE: SEDUC, 1997.

CEARÁ. Resolução No 394/2004. Fixa normas para a educação de alunos com necessidades educacionais especiais, no âmbito do Sistema de Ensino do Estado do Ceará. Fortaleza: CEC, 2004. 
CEARÁ. Conselho Estadual de Educação. Resolução N 436/2012. Fixa normas para a Educação Especial e para o Atendimento Educacional Especializado - AEE - dos alunos com deficiência, Transtornos Globais do Desenvolvimento - TGD, Altas Habilidades/Superdotação no âmbito do Sistema de Ensino do Estado do Ceará. Fortaleza: CEC, 2012.

CEARÁ. Centro de Referência em Educação e Atendimento Especializado do Ceará CREAECE. Fortaleza: SEDUC, 2015. Disponível em:

http://www.seduc.ce.gov.br/images/Desenvolvimento_da_Escola/diversidade/educacao_espec ial/acoes_programas_educacao_especial.pdf. Acesso em: 02 jun. 2018.

CEARÁ. Conselho Estadual de Educação. Resolução n ${ }^{\circ}$ 456/2016. Fixa normas para a Educação Especial e para o Atendimento Educacional Especializado (AEE) dos alunos com deficiência, Transtornos Globais do Desenvolvimento (TGD), Altas Habilidades/Superdotação, no âmbito do Sistema de Ensino do Estado do Ceará. Fortaleza: SEDUC, 2016a. Disponível em: http://www.seduc.ce.gov.br/index.php/ouvidoria/204desenvolvimento-da-escola/diversidade-e-inclusao-educacional/educacao-especial/11294educaca-especial. Acesso em: 02 jun. 2018.

CEARÁ. Lei N. ${ }^{\circ}$ 16.025/2016. Dispõe sobre o Plano Estadual de Educação (2016/2024). Fortaleza: ALCE, 2016b.

DOURADO, L. F. Avaliação do plano nacional de educação 2001-2009: questões estruturais e conjunturais de uma política. Educ. Soc., Campinas, v. 31, n. 112, p. 677-705, jul./set., 2010. Disponível em: http://www.cedes.unicamp.br. Acesso em: 11 jul. 2018.

FIGUEIREDO, R. V. As políticas regionais de educação especial no Nordeste. 26 REUNIÃO ANUAL DA ANPED, n. ed., 2003. Anais Novo governo novas políticas? Poços de Caldas: ANPED. p. 19-38. Disponível em: http://26reuniao.anped.org.br/. Acesso em: 20 maio 2018.

KASSAR, M. de C. M. Percursos da constituição de uma política brasileira de educação especial inclusiva. Rev. Bras. Ed. Esp., Marília, v. 17, p. 41-58, maio/ago., 2011.

LANCILLOTTI, S. S. P. Deficiência e trabalho. Campinas - SP: Autores Associados, 2003.

MATOS, I. S. Formação continuada dos professores do AEE: saberes e práticas pedagógicas para a inclusão e permanência de alunos com surdocegueira. 2012. 218f. Dissertação, Mestrado em Educação, Centro de Educação, Universidade Estadual do Ceará, Fortaleza, 29/12/2012.

MATOS, K. S. L. de. Pesquisa Educacional: O prazer de conhecer. Fortaleza: Edições Demócrito Rocha, UECE, 2001.

PIETRO, R. G. Educação especial em municípios paulistas: histórias singulares ou tendência unificadora? In: BAPTISTA, C. R.; JESUS, D. M. de. (Orgs). Avanços em políticas de inclusão: o contexto da educação especial no Brasil e em outros países. 3. ed. Porto Alegre: Mediação, 2015. 


\section{Como referenciar este artigo}

SANTOS, Geandra Cláudia Silva. Organização da educação especial em uma rede estadual de ensino sob o prisma das políticas públicas. Revista on line de Política e Gestão Educacional, Araraquara, v. 23, n. 1, p. 49-60, jan./abr., 2019. E-ISSN: 1519-9029. DOI: 10.22633/rpge.v23i1.11659

Submetido em: 09/12/2018

Revisões requeridas: $13 / 12 / 2018$

Aprovado em:28/12/2018

Publicado em: 02/01/2019 